\title{
A Critical Interrogation of Development Theories
}

\author{
Sandra Adriana Khonglah* \\ (Ph.D Research Scholar in the Department of Sociology, North Eastern Hills University, Shillong, India)
}

\begin{abstract}
Development is the slogan and aspiration of every Nation. It is an integral part of every Nation's policy concerned. Studies on Development have also been carried out extensively in various fields of study or disciplines. However, the explicit meaning of development has not been very clear to most people as they either understand development synonymously with modernisation or economic development. Based on this concern, this article attempts to explicate the meaning of development by providing a conceptual clarity and by analysing the different theories of development. In the light of analysing and understanding the different theoretical perspectives of development, the article also attempts to critically highlight the flaws of development theories.
\end{abstract}

Keywords: Development, progress, modernisation, economic development, transformation.

\section{INTRODUCTION}

Development is a progressive transformation towards the objectives or values that every nation aspires to achieve. It is a process of change involving progressive improvement in the quality of life of the people. Development is understood differently by different fields of study. Sociologically, development is understood in terms of the progress of society towards the betterment and standard in the life of the people. 'Development' implies the progress and stage of advancement. T.B. Bottomore sees that the term 'Development' is applicable to two social processes- growth of knowledge and, growth of human control over the natural environment as revealed and reflected by technological and economic efficiency (1986:285).

Smelser and Lipset (1966:2) see that 'Development' involves a complex series of changes at the level of social structure of developing society. The changes in one sector of social structure of developing society demands for changes in the other sectors. This definition implies that there is a chain-reaction of changes between one part of social structure and another, that is, a change in one part of social structure influences the other parts of social structure and thus leads to a gamut of changes in the whole social structure. This view of development is further elucidated in the following theoretical interpretation of development.

Further 'Development' is also viewed as the movement of the whole system of society towards an even and large measure of power to the people for their conscious participation in building their own future, higher production, equal distribution and ecologically sound environment (Sharma \& Malhotra 1977:34). This definition implies the change in the political system of society wherein optimum power is transferred to the people who took the initiative in transforming and building a better future with higher production, equal distribution, and ecologically sound environment. It is through the conscious participation and attempts of the people that development is witnessed in the society.

Development is thus a product of the conscious actions of human beings. Development would not be possible without the rationalistic attitude and actions of human beings. In fact the rationalistic attitude is the antecedent of all forms of social change such as the birth of industrialisation or capitalism or even the family planning system, etc. Auguste Comte (1915) the Father of Sociology has also rightly stated that the human mind undergoes intellectual growth. And it is this intellectual growth of the human mind that leads to the process of the development of society. However, it cannot be denied either that the rationalistic attitude of human beings also gets moulded with each phenomenon of social change and development. Human beings learnt and began to think about the other new possible ways of meeting their desired goals and objectives, which are reflected in each new phenomenon of development. For instance the invention of a new technology is the product of the conscious actions of human beings and in order to improve the efficacy of a technology, human beings started looking for new ways and new inventions. So this is how the rationalistic attitude of human beings gets moulded and reconstructed with each level and phenomenon of development. Similarly, the strategies of development formulated from time to time reflected that the rationalistic attitude of human beings get moulded and reconstructed from the experiences of the past phenomenon of development. 


\section{CONCEPTUAL CLARITY}

It can be pointed out that 'Development' in everyday usage is taken to be equated with the terms 'Economic Development' and 'Modernisation', which needs conceptual clarity. 'Development' is a desirable, continuous, evaluated, progressive change. The term development indicates progress, advancement or improvement. The term 'Development' perhaps should be used and applied to refer to any particular aspect of change that is gradually unfolding, evolving and advancing with time. 'Development' is a concept used to analyse the progress of changes brought by modernisation. Development has various aspects whose concepts differ from one particular aspect to another, for instance, economic development, technological development, political development, cultural development and so on. 'Economic development' which is widely synonymous with the term 'Development' is just one of the aspects of development which implies the quantitative increase in the output of a country brought about by the use of new technological arrangements (BaG 2001:6). Further 'Economic Development' as defined by Mehta (1999:11) refers to "growth of economic goods and services necessary for a good society characterised by more of pleasure and less of pain to its people and a conducive atmosphere for leading a harmonious life". Thus it is an increase in the value of all goods and services produced in an economy.

The term 'Modernisation' on the other hand is generated to comprehend the set of changes that affects the whole society. The concept of Modernisation is broader and it encompasses the transformation in the economic, political and, socio-cultural domain of society (Singh 2010:200). The concept indicates a break away from tradition. No society is without the influence of modernisation but the degree of influence varies from one society to another.

Development does not denote and is not equivalent to modernisation, since when we talk about it, we usually refer it to the progress of change or changes that is or are unfolding. While, 'Modernisation' as a broader concept of change, does not always refers to the progress of change but rather to the set of changes enveloping the entire society. However, development is a constituent part of modernisation. In fact there would be no modernisation without the involvement of development in its process. There would be no multiplicity of extensive innovations without the presence of development in one aspect of change or the other. For instance, because there is development in the attitudes, values and knowledge of people, new changes keep on enveloping the society like technological change, political change, economic change etc.

Though development is a constituent part of modernisation, it does not confer that all changes brought by modernisation are developed, because there are some changes that the society considers as undesirable. Some changes of modernisation are desirable while some are not, and only those changes develop which the society observes and considers as desirable. So modernisation in itself is not always considered as a positive change, while development is considered as a positive and desirable change by the society. The society in trying to realise its goals, identifies the changes, and works towards those changes for their development and ultimately, for the development of the society.

Thus, development cannot be viewed purely as an economic phenomenon nor it can be construed and understood as modernisation because when we talk of modernisation, we talk about it as a gigantic process which transforms the structure and culture of the society. However, development is just a part of modernisation that designates progress of the transformation in one part of the structure or culture of the society. It is thus a positive change. It is also a long term phenomenon because it is planned, unlike the other processes of change which are short term and unpredictable. In order to achieve something better, a society identifies the specificities and keeps in mind the objectives it wants to achieve. The society consciously attempted certain actions in order to achieve the objectives. Thus development is a positive change, a long term phenomenon and a product of the conscious attempt of the people.

\section{THEORETICAL INTERPRETATION OF DEVELOPMENT:}

In order to have a better understanding of the concept of development, it is necessary to look into how the different thinkers interpret development. The concept of development would be meaningless without applying and referring to the intellectual thoughts contributed by the renowned thinkers. The following is the discourse on the concept of development based on the theoretical perspectives put forward by the different thinkers.

Karl Marx measures development in society in terms of the accumulation of more advanced economic means of production that leads to the transformation of society eventually through class struggle. He emphasises the role of classes and class antagonisms at every stage of the mode of production, which plays an important role in leading the society towards the stage of economic development. For him 'the history of all human society, past and present, has been the history of class struggles' (Marx \& Engles. 1944:22). In his famous classic 'The Communist Manifesto' (1848), he emphasises and appreciates the capitalist society for its capability in promoting social and economic changes. According to him the capitalist society is a society that undergoes a process of radical change. But he also believes that just as capitalism replaced feudalism, capitalism itself will be replaced by communism- a classless society. In a well-known passage of The Communist Manifesto he

DOI: $10.9790 / 0837-2107023440 \quad$ www.iosrjournals.org $\quad 35 \mid$ Page


describes that "the weapons with which the bourgeoisie overthrew feudalism are now being turned against the bourgeoisie itself" (ibid:. 1944: 27). Its modern version could be seen in the fact that the ownership of the means of production is with the communist government, which promotes freedom and material progress and that comprehensive development planning leads to economic advancement in underdeveloped countries (Pandey 1986: 81).

Karl Marx theory of development has become one of the classics, yet it is not without any deficiency. Karl Marx studies development solely in terms of conflicts over the economic forces. He even attributed the social and political development of the society as the result of the economic factors. However, development in a society does not take place only on account of economic factors. He failed to recognise other factors that cause development like growth of knowledge for instance. The conflict of classes which he attributed due to economic factors is also bias. Conflicts may also be due to other factors like cultural differences, etc.

Another classical theory of development is the theory given by Emile Durkhiem (1948). Durkhiem viewed development in terms of changes in the structure of society and nature of social relationships of people. He said that the changes in the structure of the society lead to changes in the nature of the social relationships of people. The changes in the structure of the society are featured by the increased in size of population, increased division of labour or increased functional differentiation and specialisation, stratification, etc. The change in the social relationship of people is featured by the relationship based on objective measures due to social differentiation and individualism. People are no longer tied together by closely knit relationship which he called 'mechanical solidarity', but they integrate, interdependent and cooperate together to meet their needs which he called 'organic solidarity'. '.......organic solidarity arose because of complimentarily between actors engaged in different pursuits' of the modern world (Durkhiem 1984: XVI).

Durkhiem's theory of development have proved to be useful in the study of development, since it talked about the changes in both structure of society and social relationship of people, which indicates advancement and progress of the society from simple to complex or pre-industrial to industrial. However, his concept of 'mechanical solidarity' which characterised close knit relationship and less economic differentiation among the people in simple societies is deemed unfit in the study of social relationship and economic arrangement of people in the pre-industrial Indian society, where the people were highly differentiated economically and socially because of caste system. There existed no close knit social relationship except social distance relationship among people of different caste groups. The economic undertakings of people of different caste groups were differentiated by their birth and ascribed status. Thus the 'mechanical solidarity' prevailing in simple societies described by Durkhiem cannot be applied in the study of simple pre-industrial society in India. The theoretical formulation of the concept of 'mechanical solidarity' was generalised by Durkhiem.

Max Weber believed that the growth of rationality or the process of rationalisation determines development in a society. In his doctoral thesis 'The Protestant Ethic and the Spirit of Capitalism' (1905), he characterised the capitalist world by its rationalistic attitude. He held that the protestant sect influenced a large number of people engaged in work to develop the spirit of capitalism. For Weber religion thus played an important role in inculcating and inducing people with an attitude of economic rationality that led to the growth of capitalism in the west, which for him is 'Development'. Influenced by the views of Max Weber, about how rationality brought development in society, Jurgen Habermas (1984,1985), developed his own contemporary thought about development. According to him, the society is developed if both the 'life world' and 'system world' mutually expressed their rationality without dominating one another. He believed that the 'life world' which is the world of everyday life where free interpersonal communication exists is being destroyed and dominated by the rationality of the 'system world' (system of governance). For instance, in the west this domination has become so strong that it even penetrated the private affairs of family life. It is the legal system that decided how many children a family should have.

It is observed that the rationalisation of the society is development for both these thinkers. However, the difference lies in the fact that the former talked about economic rationality while the latter was concerned about communicative rationality. Webers' theory explicated the relationship between religion and economy, about how religion influenced the growth of economic rationality among the people. However, one shortcoming with this theory is that economic rationality may also developed independently of the religious ethics. Economic rationality may developed in an individual as part of the intellectual growing phase or due to the individuals' experienced of economic condition which motivated them to achieve and accumulate wealth and not by the influence of religious ethics alone. Jurgen Habermas, though he emphasised that both the 'life world' and 'system world' should be allowed to express their rationality in their own way, he was so much into the critical representation of the domination of the 'life worlds' rationality by the 'system world'. It appears in his writings that he appreciated the rationality of the 'life world' and condemned the rationality of the 'system world' instead of perceiving it as one of the contemporary forms of development process.

Parsons' pattern-variables (1951) are equally important mechanisms for determining development in a social system. The pattern-variables of ascription Vs achievement, particularism Vs universalism and, functional diffuseness Vs specificity of functions are important tools to analyse and distinguish between traditional and 
developed social systems. He conceived a social system as developed if it is based on achievement, universalism, and functional specificity. Hoselitz (1960) applied the above pattern-variables of Parsons in his empirical study of economic development. According to him, economically advanced countries exhibited the pattern-variables of achievement, universalism and functional specificity. He says that the allocation of economic goods and assigning of economic objects in economically advanced countries is purely based on the norm of achievement. Further in analysing economic development of developed countries, Hoselitz argues, the prevalence of the principle of universalism in the distribution of economically relevant tasks, as well as the specificity of economic roles resulting from the specialisation of economic tasks and ever increasing division of social labour ( Hoselitz 1960: 30-33). These characteristic features found in developed countries were absent in the developing countries says Hoselitz. The weakness of this theory is that it made use of generalisations. Hoselitz made a generalised analysis of the social systems or countries featuring development or underdevelopment on the basis of certain dichotomous key features. He failed to analyse the features that determined development or underdevelopment of countries based on their experiences and realities. Thus this theory is empirically unfavourable.

Smelser's theory of structural differentiation (1965), provides an enlightened understanding of the process of development. He opines that development proceeds only through the interplay of differentiation and integration (Smelser 1965: 110). He says that as societies evolved, there develop changes at the level of structure. Multiplicity of differentiated structures or the complex specialised structures began to spring up. He argued that during the development process there exist social disturbances and conflicts, problems of integration and of coordinating the activities of various new institutions. Smelser tried not to look at the pessimistic view that these social disturbances and integrative problems would hamper the process of development but he was optimistic by viewing that these disturbances would serve as engine of progress and would only ...... " shape the course of future processes of differentiation" (Ibid: . 115) and specialisation, and that the new differentiated integrative devices like unions, associations, clubs, government regulations and so on, will provide stability and integration and thus lead to development in society.

Smelser while describing his theory of structural differentiation cited examples of changes in family structure, economic structure, etc but failed to provide an intensive explanation of the phenomena. Structural differentiation, changes, social disturbances, are phenomena that are generally observed everywhere in the world, especially in emerging societies of the third world and Smelser does also offer a generalised explanation of the phenomena. He is empirically weak in describing the phenomena.

Andre Gunder Frank, who is largely associated with the Dependency Theory of Development, opines that development cannot be viewed in isolation or independent of Underdevelopment. Infact, there is a linkage between development and underdevelopment which provides the idea of the notion of development, in the sense that, the generation of development in one area consequently leads to a simultaneous generation of underdevelopment in some other area (Frank 1969: 4). Frank believes that the capitalist world is based on a chain of metropolis-satelite relations and that "these relations are essential part of the structure and development of the capitalist system on a world scale as a whole" (ibid:.4). He argues that the 'Metropolis' or rich countries develop by expropriating the economic surpluses of the 'Satellites' or poor countries. The global economic development of the metropolitan countries historically stems from their exploitation of poor countries or 'Satellites'. Frank went on to argue further that this metropolis-satelite relation is not limited to the international level but could be found even within a region or country where the metropolitan centres would economically dependent on and exploited its hinterland (ibid:.6). Thus, Frank conceptualised development by providing an understanding about how the historical process of chain relations of the metropolis and satelites, generate economic development in the former and simultaneously generate underdevelopment in the latter.

It can be understood that A.G Frank attributed everything to the metropolitan developed countries for the underdevelopment of the third world countries, and in the process he ignored to looked at the internal, structural and cultural factors which could be reasons for the slow process of development in the third world countries, eg, over population, traditional culture, little investment, etc.

The transition from underdevelopment to development must proceed a long series of steps for an American development theorist, W.W.Rostow (1960). His conception of development is the gradual improvement of the economy of the Nations towards self- sustained growth. He states that there are five stages of growth through which the economy of Nations must pass to achieve development, these are- the traditional stage; the preconditions for take-off; take-off; the drive to maturity and; the stage of high mass consumption. He regarded the Third World Countries as traditional, and that their process of economic growth is very slow. He therefore argued that they needed to develop to the second stage and thus establish the preconditions for takeoff. For establishing the preconditions for take-off, he mentions that the Nation or society needs '........to respond actively to new possibilities for productive enterprises as well as it requires changes in the political, social and institutional, which will both perpetuate an initial increase in the scale of investment and result in the regular acceptance and absorption of innovations' ( Rostow 1960: 275). Rostow argued that the industrialised countries developed because they had fulfilled the conditions necessary for the take-off towards self sustaining

DOI: 10.9790/0837-2107023440 $\quad$ www.iosrjournals.org $37 \mid$ Page


economic growth. He mentioned that 'Britain was the first of the European nations to move from the stage of preconditions into take-off........' (ibid.: 312). He therefore implied that the developing countries had only to replicate similar conditions to attain development.

The Rostowian scheme made use of generalisations in explaining development. He attempted to provide a more general perspective in the analysis of development. He talked about the passing of societies through the same stages at a certain period of time. His theory does not take into account the cultural basis in explaining development. Different societies possessed different cultures, and some societies may take time to reach a certain stage of development because of their cultural basis. The certainty of time provided by Rostow in explaining development is lacking an empirical proof. One cannot become so certain about certain time, when society would reached at a particular stage of development.

The socio-psychological understanding of development treats the 'need for achievement' or the desire to achieve as the precondition to development. The social psychologist theorist, David McClelland (1961), sees economic development as the product of achievement motivation or the need for achievement. In his book 'The Achieving Society' he focussed his interest in the investigation of the causal relation of the need for achievement (n Ach) and economic development, by studying different countries through the analyses of their children's story books, comic books, folksongs, etc, and believed that the greater the achievement motivation indicated and found in the analysis, the more likely it will indicate economic development of countries, since achievement motivation influenced economic development. Besides his macro analysis of achievement motivation of countries, he also analysed the achievement motivation of individuals. McClelland says that the people motivated by the desire to achieve, behave and act in a more rational and energetic way in order to pursue their economic objectives, especially when it comes to entrepreneurial activities. He called this as the 'mental virus' which can be infected in individuals to motivate them to behave and act differently in economic situations. This was done among the businessmen of Kakinada, a town in Andhra Pradesh, India, to improve their achievement motive through training programmes. The findings of McClelland showed that after the course, the Kakinada businessmen performed well in their entrepreneurial activities than before, they paid more attention to their business, invested and started new enterprises. Thus the author's view of development rests on the belief that the 'need for achievement' is an important stimulating psychological factor of economic development.

McClelland focussed so much on the 'need for achievement', he ignored other factors like need for resources which is also important for the economic development of countries. Though he envisaged that there is a correlation of achievement motivation and economic success of a person which is in fact found to be relevant, but on a broader perspective, his declaration of the correlation of achievement motivation and economic development of nations was found to be irrelevant. He was also highly criticised for the measurement method he adopted to study achievement motivation of different nations, stating it was not valid.

Alex Inkeles (1966:158), stresses that the idea of development requires the very transformation of the nature of man- a transformation that is both a means to the end of yet greater growth and at the same time one of the great ends itself of the development process. Inkeles looked at development from the individual aspect of change. He listed the qualities of man that involves the idea of development- the attitude of man to accept and welcome change; his readiness to form his own opinions as well as acknowledges the opinions of others; quality of appreciating and value fix time schedule; quality of believing on planning and organising and taking it as a way of handling life; quality of believing in the emancipation of traditional authority; quality of believing in calculability and in a reasonably lawful world under human control; quality of treating others with dignity and respect: quality of having more faith in the application of science and technology; and his quality of having a strong belief on distributive justice (Ibid.:161-165). A similar theory was studied earlier by Daniel Lerner (1958) in the Middle East Countries. Learner sees that the changes in the personality of an individual such as mobile personality or willingness to accept change, one who is literate, empathizes, participates in political arena, indicates development.

Both these thinkers focussed on the external forces of change such as urbanisation, industrialisation and factory system, spread of education and media communication which influenced the attitude and values of individuals. They ignored to look at the internal forces of change such as conflicts and social movements, etc. Both Alex Inkeles and Daniel Lerner undertook studies in the developing countries some of which belong to the Middle Eastern region and South Asian region such as Turkey, East Pakistan, India, etc, which may have also experienced various internal conflicts and social reform movements such as abolition of sati, solidarity and peace movements, ecological movements etc. If the exposure of individuals to the external forces of change brought changes in their attitude and personality there was likelihood for the internal forces of change to also play their part in influencing development.

'Globalisation' is an indication of advancement and development of society for Anthony Giddens (1990). He understands development from the context of 'globalisation'- the interplay of modern institutional organisations and the intensification of the interrelations of individuals across time and space. Giddens, is a contemporary thinker, and in his explanation of the phenomenon of globalisation, he made an effort to provide 
various theoretical bits and pieces which in the end made his work eclectic, complex and fragmented which is difficult to understand. His theory is merely descriptive.

Unlike the western understanding of development, the Gandhian concept of development focuses on the reconstruction of villages through non-violence, self governance and self sufficiency so far as the basic necessesities are concerned. The village at the local level would be the focal point of economic development in the Gandhian scheme. He discourages industrialisation because both natural resources and human potentialities are drawn from the rural areas, hence weakens the development of the rural areas. According to him industrialisation replaces man power and hence adds to unemployment. He thus, encourages setting up of village and cottage industries for they provide employment to meet the needs of the villagers and facilitate village self sufficiency (Shah \& Chaturvedi 1983:34). He also encourages the decentralisation of social and political power. Decision making at the local level through institutions such as panchayats would have the power to exercise legislative, executive, and judicial functions, thereby would look after education, health and sanitation of the village. In this way the village would manage its own affairs and thus would be prepared to perish (Ibid.:33). Thus in his view the development at the village level is essential in order to call for development at the national level.

There has been a major misconception about Gandhi's model of development. Some regarded that he gave a narrow concept of development for he opposed modern civilisation, but there are those who supported Gandhiji's thought cleared out the rationale of his thought about development. They argued that Gandhi did not oppose the use of modern science and technology as long as they did not dehumanised human labour. Gandhi regarded India as an agrarian country, hence recognises the need of scientific development of agriculture and cottage and small scale industries. However in India today, Gandhi's model of development is practicing side by side with other modern strategies of development.

\section{CONCLUSION}

From the above discussion it is understood that development has an ideological basis. There are no standard parameters that determine development. Thus the different thinkers viewed and conceptualised development from different perspectives. They advocate and stress different sets of economic and social factors that lead to development. To recapitulate, some viewed that the emergence of new productive technologies or expansion of economic undertakings or tasks, increased economic efficiency etc, implies development. Some indicated that the progress of society towards a state of rationalisation is development. Some others accounts that development has a historical root in the colonial period. In other words, it is a product of the historical linkage between two or more Nations. Development is also viewed as the improvement of the economic conditions of the Nations from one stage to another. Still some others were of the opinion that development is a product of the psychological factor, that is, the 'need for achievement' or that development is a product of the individual's attitudinal change. Thus the psychological state of mind is also one of the great contributors to development. Though the perspectives of development given by the different thinkers have their own limitations, yet they have become the basic foundation in the study of development world-wide. These theories immensely provide an insightful understanding of development from different aspects.

\section{REFERENCES}

[1]. BaG, G. N.2001. Rural Transformation in Tribal Areas. New Delhi: Akansha Publishing House.

[2]. Bottomore, T. B. 1986. Sociology- A guide to problems and literature. Bombay: Blackie and Sons (India) Ltd.

[3]. Comte, Auguste. 1915. The Positive Philosophy, Harriet Martineau,trans. and ed. London: George Bell and Sons.

[4]. Durkhiem, Emile. 1984. The Division of Labour in Society. Houndmills: Macmillan Publishers Ltd.

[5]. Frank, A. G. 1969. Under-development or Revolution: Essays on the development and the immediate enemy. New York: Monthly Review Press.

[6]. Giddens, Anthony.1990. The Consequences of Modernity. Cambridge: Standford University Press.

[7]. Hoselitz, Bert F. 1960. Sociological Aspects of Economic Growth. New Delhi: Amerind Publishing Co Pvt Ltd.

[8]. Habermas, Jurgen.1984. The Theory of Communicative Action, Volume one: Reason And The Rationalisation of Society. Boston: Beacon Press.

[9]. Habermas, Jurgen. 1985. The Theory of Communicative Action, Volume 2: System and Lifeworld: A Critique of Functionalist Reason. Boston: Beacon Press.

[10]. Inkeles, Alex. 1966. 'The Modern Man', in Myron Weiner (eds.). Modernization- The Dynamics of Growth. London: Inc Publishers.

[11]. Lerner, Daniel.1958. The Passing of Traditional Society: Modernising the Middle East. New York : The Free Press. 
[12]. Marx, K \& F. Engles.1944. Communist Manifesto, With an Introduction and Explanatory Notes by Prof. Ryazanoff. Calcutta: National Book Agency Private Limited.

[13]. McClelland, David C and Winter, David G. 1969. Motivating Economic Achievement. New York: The Free Press.

[14]. McClelland, David C. 1961. The Achieving Society. New York: The Free Press.

[15]. Mehta, S. R. 1999. Dynamics of Development. New Delhi: Gyan Publishing House.

[16]. Parsons, T. 1951. The Social System. London: Routledge \& Kegan Paul.

[17]. Pandey, Rajendra. 1986. Sociology of Underdevelopment: Theories and Critiques. Delhi: Mittal Publications.

[18]. Rostow, W.W. 1960. The Process of Economic Growth. London: Oxford University Press.

[19]. Shah, Ghanshyam \& H. R. Chaturvedi.1983. Gandhian Approach to Rural Development. Jawaharnagar Delhi: Ajanta Publications.

[20]. Sharma, S. K \& S. L. Malhotra. 1977. Integrated Rural Development, Approach, Strategy and Perspective. New Delhi: Abhinav Pulications.

[21]. Singh, Sheobahal. 2010. Sociology of Development. Jaipur: Rawat Publications.

[22]. Smelser, Neil J. \& Seymour Martin Lipset.1966. Social Structure and Mobility in Economic Development. London: Routledge \& Kegan Paul.

[23]. Smelser, Neil J. 1965. The Sociology of economic life. New Delhi: Prentice-Hall of India (Private) Ltd.

[24]. Weber, Max.1905. The Protestant Ethics and Spirit of Capitalism. London: Unwin University Books. 